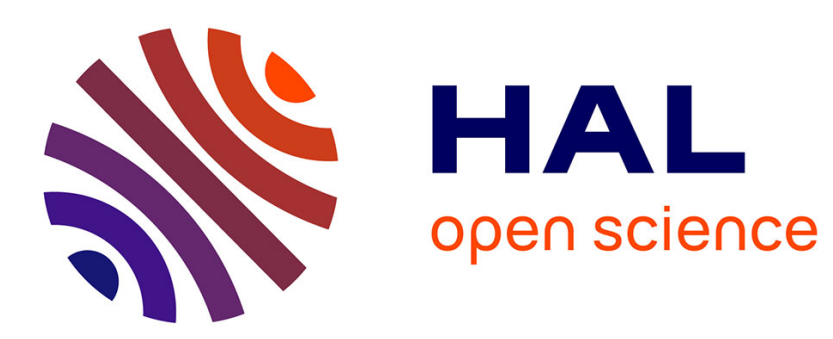

\title{
WaterNet: the NASA Water Cycle Solutions Network
}

P. Houser, D. Matthews, M. Brilly

\section{To cite this version:}

P. Houser, D. Matthews, M. Brilly. WaterNet: the NASA Water Cycle Solutions Network. Advances in Science and Research, 2007, 1, pp.23-26. hal-00297445

\section{HAL Id: hal-00297445 \\ https://hal.science/hal-00297445}

Submitted on 6 Dec 2007

HAL is a multi-disciplinary open access archive for the deposit and dissemination of scientific research documents, whether they are published or not. The documents may come from teaching and research institutions in France or abroad, or from public or private research centers.
L'archive ouverte pluridisciplinaire HAL, est destinée au dépôt et à la diffusion de documents scientifiques de niveau recherche, publiés ou non, émanant des établissements d'enseignement et de recherche français ou étrangers, des laboratoires publics ou privés. 


\title{
WaterNet: the NASA Water Cycle Solutions Network
}

\author{
P. Houser ${ }^{1}$, D. Matthews ${ }^{2}$, and M. Brilly ${ }^{3}$ \\ ${ }^{1}$ Center for Research on Environment and Water \& George Mason University, Calverton, MD 20705, USA \\ ${ }^{2}$ Hydromet DSS, LLC, Silverthorne, CO 80498-1848, USA \\ ${ }^{3}$ FGG University of Ljubljana, Slovenia
}

Received: 10 February 2007 - Revised: 29 March 2007 - Accepted: 14 April 2007 - Published: 6 December 2007

\begin{abstract}
This paper provides an over view of a new international network of researchers, stakeholders, and end-users of remote sensing tools that will benefit the water resources management community. It discusses the concept of solutions networks focusing on the WaterNet and it invites EGU teams to join the in the initial stages of our WaterNet network. The NASA Water cycle Solutions Network's goal is to improve and optimize the sustained ability of water cycle researchers, stakeholders, organizations and networks to interact, identify, harness, and extend NASA research results to augment decision support tools and meet national and international needs. This paper seeks to invite EU scientific teams and water resource management teams to join our WaterNet Solutions Network.
\end{abstract}

\section{Background and plan}

Earth is a unique, living planet due to the abundance and vigorous cycling of water throughout the global environment. Water is essential to life and directly impacts and constrains society's welfare, progress, and sustainable growth, and is continuously being transformed by climate change, erosion, pollution, and engineering practices. The water cycle is a critical resource for industry, agriculture, natural ecosystems, fisheries, aquaculture, hydroelectric power, recreation, and water supply, and is central to drought, flood, transportationaviation, and disease hazards. It is therefore a national priority to use advancements in scientific observations and knowledge to develop solutions to the water challenges faced by society. NASA's unique role is to use its view from space to improve water and energy cycle monitoring and prediction. NASA has collected substantial water cycle information and knowledge that must be transitioned to develop solutions for all twelve National Priority Application (NPA) areas. NASA cannot achieve this goal alone - it must establish collaborations and interoperability with existing networks and nodes of research organizations, operational agencies, science communities, and private industry.

Therefore, we are developing WaterNet: The NASA Water Cycle Solutions Network, whose goal is to improve and optimize the sustained ability of water cycle researchers, stakeholders, organizations and networks to interact, identify, har-

Correspondence to: P. Houser

(hydrometdss@comcast.net) ness, and extend NASA research results to augment decision support tools and meet national needs. We will develop WaterNet by engaging relevant NASA water cycle research resources and community-of-practice organizations to develop what we term an "actionable database" that can be used to communicate and connect NASA Water cycle research Results (NWRs) towards the improvement of water-related Decision Support Tools (DSTs). An actionable database includes enough sufficient knowledge about its nodes and their heritage so that connections between these nodes are identifiable and robust. Recognizing the many existing highly valuable water-related science and application networks in the US and EU, we will focus the balance of our efforts on enabling their interoperability in a solutions network context. We will initially focus on identification, collection, and analysis of the two end points, these being the NWRs and water related DSTs. We will then develop strategies to connect these two end points via innovative communication strategies, improved user access to NASA resources, improved water cycle research community appreciation for DST requirements, and improved identification of pathways for progress. Finally, we will develop relevant benchmarking and metrics, to understand the network's characteristics, to optimize its performance, and to establish sustainability. Figure 1 shows the NASA solutions approach. The WaterNet will deliver numerous pre-evaluation reports that will identify the pathways for improving the collective ability of the water cycle community to routinely harness NWRs that address crosscutting water cycle challenges.

Published by Copernicus Publications. 


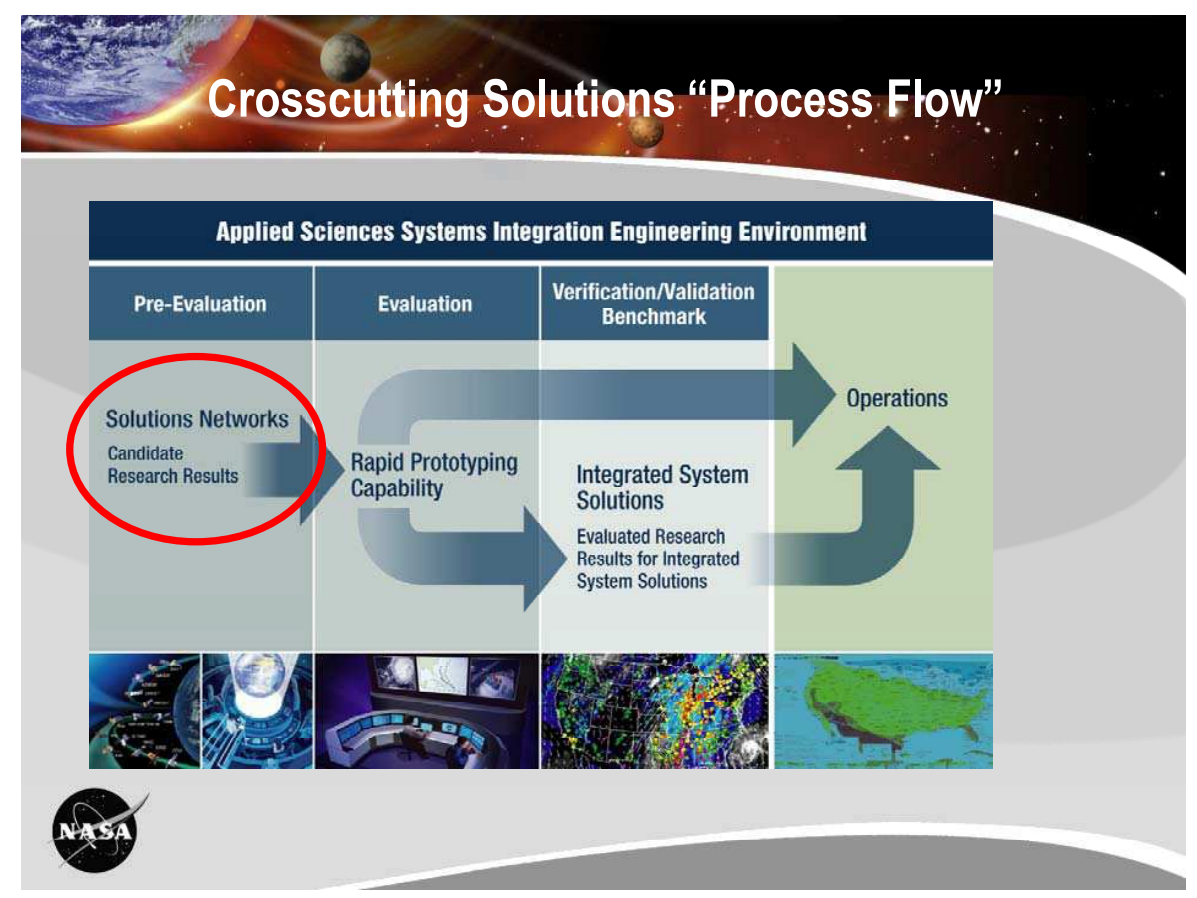

Figure 1. Applied Science Systems Integration Engineering Environment.

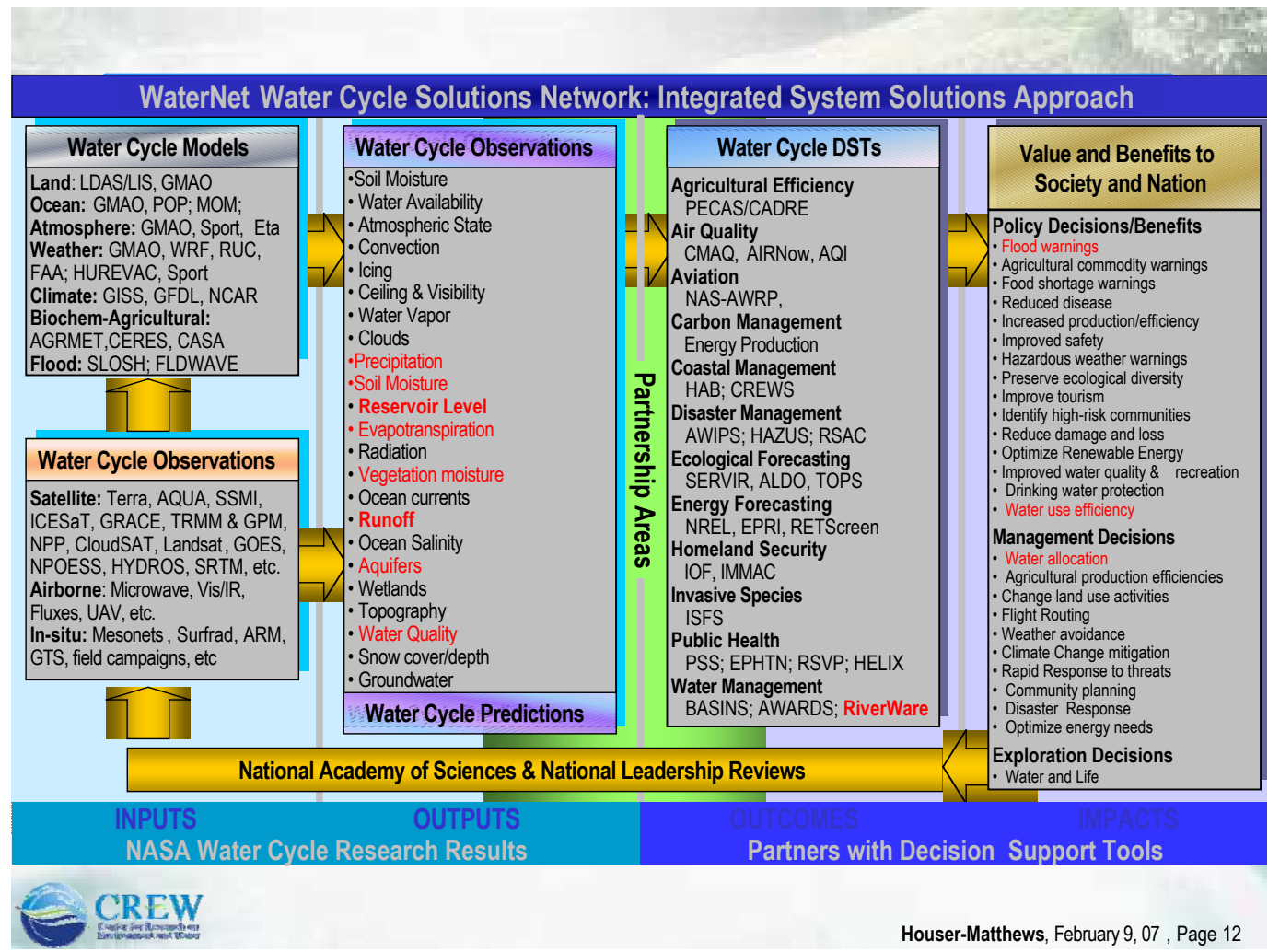

Figure 2. The WaterNet Water Cycle Solutions Network approach to integrated system solutions from observations and models to models, and predictions into decision support tools (DSTs) that yield value and benefits to society - a network between research and end-users with DSTs. 
Table 1. Selected water-cycle related science and stakeholder networks to be engage by WaterNet for solutions networks.

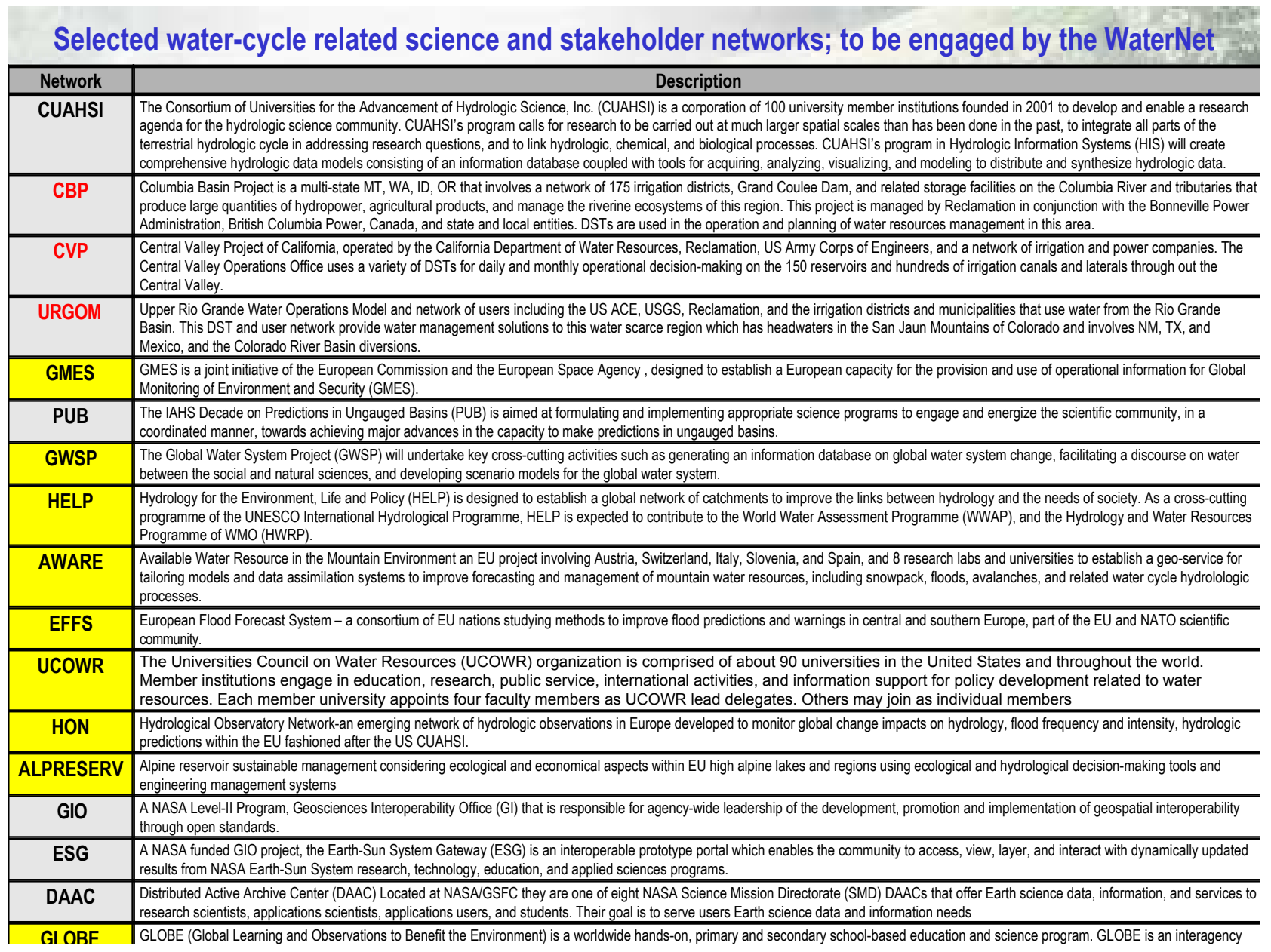

Our team will develop WaterNet by engaging relevant NASA water cycle research resources and community-ofpractice organizations, to develop what we term an "actionable database" that can be used to communicate and connect NASA Water cycle research Results (NWRs) towards the improvement of water-related Decision Support Tools (DSTs). An actionable database includes enough sufficient knowledge about its nodes and their heritage so that connections between these nodes are identifiable and robust. Recognizing the many existing highly valuable water-related science and application networks, we will focus the balance of our efforts on enabling their interoperability in a solutions network context. We will initially focus on identification, collection, and analysis of the two end points, these being the NWRs and water related DSTs. We will then develop strategies to connect these two end points via innovative communication strategies, improved user access to NASA resources, improved water cycle research community appreciation for DST requirements, improved policymaker, management and stakeholder knowledge of NASA research and application prod- ucts, and improved identification of pathways for progress. Finally, we will develop relevant benchmarking and metrics, to understand the network's characteristics, to optimize its performance, and to establish sustainability. The WaterNet will deliver numerous pre-evaluation reports that will identify the pathways for improving the collective ability of the water cycle community to routinely harness NWRs that address crosscutting water cycle challenges. Figure 2 shows the approach for integrating key elements.

Our tightly-knit team is composed of leading experts in NASA water cycle science, the water sector user community, and organizational connections and communications design and optimization. The team represents a strategically placed set of national and international organizations that will partner to harness NWRs to characterize and improve networks that sustain NPA solutions. Already established partnerships represent a cross-section of individual and networked NWRs and DSTs from government, private, and academic domains, that will enable us to quickly establish an operational solutions network, entrain more partner nodes and networks, 
and move WaterNet toward self-sustainability. EU projects like AWARE, GEOSS, GMES and the Flood Forecasting Research projects are potential projects that may directly benefit from this WaterNet networking. Table 1 shows the existing science and stakeholder networks to be engaged by WaterNet.

\section{Summary and conclusion}

WaterNet is a newly emerging network of water and energy cycle researchers and end-user stakeholders and water managers designed to improve the water resource, energy, and disaster management decisions by demonstrating value added from research. It seeks new partners from the EMS and EGU research and decision-making community. If interested please contact hydrometdss@comcast.net.

Edited by: M. Brilly

Reviewed by: M. Mikoš

\section{References}

\section{Relevant web pages:}

CUAHSI - http://www.cuahsi.org

(The Consortium of Universities for the Advancement of Hydrologic Science, Inc.).

CBP - http://www.usbr.gov/dataweb/html/columbia.html (Columbia Basin Project).
CVP - http://www.usbr.gov/dataweb/html/cvp.html (Central VAlley Project of California).

URGOM - http://www.spa.usace.army.mil/urgwom/default.asp

(Upper Rio Grande Water Operators Model).

GMES - http://www.gmes.info/

(Global Monitoring of Environment and Security).

PUB - http://pub.iwmi.org/UI/Content/Default.aspx?PGID=0

(Predictions in Ungauged Basins).

GWSP - http://www.gwsp.org/

(Global Water System Project).

HELP - http://portal.unesco.org/sc_nat/ev.php?URL_ID=1205 $\& U R L \_D O=D O \_T O P I C \backslash \& U R L \_S E C T I O N=201$

(Hydrology for the Environment, Life and Policy).

AWARE - http://www.aware-eu.info/

(Available Water Resource in the Mountain Environment).

EFFS - http://effs.wldelft.nl/index.htm

(European Flood Forecast System).

UCOWR - http://www.ucowr.siu.edu/

(Universities Council on Water Resources).

ALPRESERV - http://www.alpreserv.eu/

(Alpine reservoir sustainable management).

GIO - http://gio.gsfc.nasa.gov/

(Geosciences Interoperability Office)..

ESG - http://esg.gsfc.nasa.gov/web/guest/home

(Earth-Sun System Gateway).

DAAC - http://edcdaac.usgs.gov/

(Distributed Active Archive Center).

GLOBE - http://www.globe.gov/globe_flash.html

(Global Learning and Observatories to Benefit the Environment).

EOS - http://gcmd.nasa.gov/records/EOSDIS-ECHO.html (ClearingHOuse ECHO). 